Revue d'histoire de l'Amérique française

REVUE D.HISTOIRE DE L'AMÉRIQUE FRANÇAISE

\title{
La Révolution française sur les rives du Saint-Laurent
}

\section{Michel Brunet}

Volume 11, numéro 2, septembre 1957

URI : https://id.erudit.org/iderudit/301830ar

DOI : https://doi.org/10.7202/301830ar

Aller au sommaire du numéro

Éditeur(s)

Institut d'histoire de l'Amérique française

ISSN

0035-2357 (imprimé)

1492-1383 (numérique)

Découvrir la revue

Citer cet article

Brunet, M. (1957). La Révolution française sur les rives du Saint-Laurent. Revue d'histoire de l'Amérique française, 11(2), 155-162.

https://doi.org/10.7202/301830ar d'utilisation que vous pouvez consulter en ligne.

https://apropos.erudit.org/fr/usagers/politique-dutilisation/ 


\section{LA RÉVOLUTION FRANÇAISE SUR LES RIVES DU SAINT-LAURENT}

Une tradition tenace, mais non fondée, prétend que les Canadiens français ont longtemps vécu isolés du monde extérieur. Des sociologues et des économistes, s'appuyant sur des recherches incomplètes et ignorant totalement l'histoire réelle du Canada français, ont soutenu que les fondateurs de la Nouvelle-France et leurs descendants auraient formé jusqu'au $\mathrm{XX}^{\mathrm{e}}$ siècle une société paysanne semi-fermée, vivant à l'écart des grands mouvements qui ont conditionné l'évolution historique des autres nations du monde atlantique. Depuis quelques années, on entend dire et répéter sur tous les tons et dans tous les milieux que le moment est enfin venu pour les Canadiens français du Québec de renoncer définitivement à leur isolationnisme traditionnel et d'accepter une «intégration lucide» au monde contemporain.

La vérité historique est bien différente. Aux XVII et XVIII ${ }^{\mathrm{e}}$ siècles, les Canadiens ont vécu présents au monde de leur époque. Cette présence n'était pas passive mais active. Ils ont été les artisans d'une grande œuvre politique, militaire, économique et sociale en Amérique du Nord: la fondation de deux colonies françaises et la pénétration d'un continent. Après 1763, la Conquête anglaise et l'occupation étrangère de leur patrie les ont placés dans un état de servitude et leur ont enlevé la liberté d'agir comme collectivité autonome, capable d'orienter elle-même ses destinées dans l'espace et dans le temps. Mais, comme individus, ils n'avaient pas été retirés de l'actualité. Même s'ils ne jouaient plus un rôle important dans le monde atlantique, les Canadiens français furent mêlés à tous les grands événements que celui-ci a connu depuis 1763 . Rien n'est plus absurde que de croire et de laisser croire qu'ils ont vécu en vase clos.

Par exemple, il est évident que la Révolution française a profondément remué les Canadiens. Lors de la Guerre de l'Indépendance, ils n'avaient pas caché leur sympathie pour les Américains et pour les Français venus au secours de la nouvelle répu- 
blique. Moins de vingt ans plus tard, les victoires éclatantes de la France révolutionnaire exaltèrent leur imagination. Ils crurent et espérèrent que leur mère-patrie victorieuse viendrait les libérer de la domination anglaise. Cette idée était surtout répandue parmi les classes populaires. Mais n'oublions pas que celles-ci constituaient la majorité de la population. Les classes dirigeantes ou pseudo-dirigeantes, qui étaient obligées de collaborer avec les administrateurs anglais depuis la Conquête, cherchèrent à rassurer leurs maîtres sans trop mécontenter la masse de leurs compatriotes. Ceux-ci avaient pris l'habitude, depuis l'occupation du pays, de considérer les chefs de la société canadienne comme les agents stipendiés du gouvernement britannique. Ce fait explique certaines attitudes bien enracinées dans la population canadienne-française à l'égard du pouvoir politique.

D'un autre côté, il est facile de comprendre l'inquiétude des autorités ecclésiastiques et des milieux conservateurs de l'ordre établi. L'enthousiasme manifesté parmi le peuple pour la France révolutionnaire et les menaces proférées par les agitateurs contre le gouvernement et ses partisans n'avaient rien de rassurant pour les gens en place. Mgr Hubert s'en alarme au printemps de 1794: "Le respect que nous devons aux représentants de Sa Majesté ne saurait être porté trop loin, puisqu'ils sont assez réservés pour ne rien exiger de contraire à notre conscience. Ajoutez à cela que les agitations surprenantes dans lesquelles la révolution de France jette les esprits des peuples, rendent le concert entre l'empire et le sacerdoce plus nécessaire. ${ }^{1}$ L'évêque de Québec avait d'ailleurs demandé à tous les curés de rappeler à leurs paroissiens quels étaient leurs devoirs envers le gouvernement et de les mettre en garde contre la propagande française. ${ }^{2}$ Le gouverneur lui avait conseillé cette démarche. Cette lettre circulaire qui signalait la présence d'une flotte française au large des côtes de l'Atlantique, a peut-être plus contribué à favoriser l'agitation qu'à calmer les esprits. Les rumeurs d'une invasion prochaine lancées par les émissaires français et leurs

1 Mgr Hubert à l'abbé John Jones, 29 mars 1794, Rapport de l'archiviste de la province de Québec (1930-1931) : 298-299.

2 * Circulaire à MM. les Curés à l'occasion des rumeurs de guerre 》, 9 novembre 1793, Mandements des évêques de Québec, 2: 471-473. 
acolytes reçurent ainsi une confirmation officielle. Le 26 novembre 1793, le gouverneur publia une proclamation contre les fauteurs de désordre dans le but de « réprimer les desseins méchants et les pratiques séditieuses 》 et demandant aux «bons sujets de Sa Majesté » de prêter leur concours pour «découvrir toutes et chaque personnes qui pourront tenir des discours séditieux ou autres paroles tendantes à la trahison $»^{3}$ Le silence complice gardé par la population au cours de l'hiver 1793-1794 laisse croire que les «bons sujets de Sa Majesté »n'étaient pas nombreux, qu'ils n'avaient pas le triste courage de devenir délateurs ou encore qu'ils craignaient les représailles des « démocrates 》.

Le document qui suit fut rédigé en juin 1793 par le « citoyen » Genêt, premier et turbulent représentant de la République française à Philadelphie. Le ministre français avait bénéficié des conseils et des suggestions d'un jeune Canadien qui était venu lui offrir ses services. Henri Mezières, ardent admirateur des encyclopédistes et de la Révolution française, avait jugé plus prudent, au printemps de 1793 , de quitter son pays natal avec l'intention de se rendre en France. Après avoir rencontré le ministre Genêt, il compta sur celui-ci et sur la France pour libérer ses compatriotes de la domination étrangère. ${ }^{4}$ Cette brochure de huit pages, imprimée à Boston, a fort probablement circulé parmi la population dès l'automne de 1793. C'est en janvier 1794 que lord Dorchester en a remis quelques copies au procureur général, James Monk. Celui-ci conduisit une longue et patiente enquête pour découvrir les responsables de l'agitation révolutionnaire. Ses démarches donnèrent quelques résultats, mais on ne réussit pas à arrêter les véritables meneurs.

Cet appel à l'insurrection créa une grande impression. Des citoyens de Québec, de Montréal et d'ailleurs se réunirent en secret pour en prendre connaissance et pour en discuter. Les gens du peuple, toujours gouailleurs, avaient même surnommé cette petite brochure, «le Catéchisme ». Serait-ce notre premier 24-25.

3 Rapport des Archives publiques du Canada (1921), Appendice B,

4 Voir Mason Wade, «Quebec and the French Revolution of 1789 : The Missions of Henri Mezières 》, Canadian Historical Review, 31 (décembre 1950) : $345-368$. 
Catéchisme des électeurs? On en fit des copies manuscrites pour en faciliter la diffusion. Des propagandistes habiles parcoururent les campagnes pour communiquer la bonne nouvelle aux paysans et villageois. Aux jours de marché, on ne parlait pas uniquement légumes, bétail et température. En quelques endroits, des lecteurs publics improvisés se chargèrent de faire la lecture de ce manifeste à la porte des églises ou sur les places publiques. Les autorités locales - seigneurs, juges de paix, curés et capitaines de milice - donnent l'impression d'avoir souvent fermé les yeux. Avaient-ils peur de provoquer la colère populaire en prenant la défense du gouvernement britannique et en dénonçant la propagande de la France révolutionnaire ?

$\mathrm{Au}$ printemps de 1794 , de graves émeutes éclatèrent dans les régions de Montréal et de Québec. Le calme ne se rétablit que graduellement. Des événements semblables se répéteront en 1796.

Lisons maintenant le «Catéchisme» qui circulait sous le manteau au cours de l'hiver de 1793-1794 dans la «bonne» province du Bas-Canada. On se rendra compte que nos ancêtres ne vivaient pas en dehors du monde atlantique. ${ }^{5}$

Université de Montréal.

Michel BRUNET

\section{LES FRANÇAIS LIBRES À LEURS FRËES LES CANADIENS}

Lorsque nous gémissions sous un gouvernement arbitraire, nous ne pouvions que plaindre votre sort, regretter les liens qui nous unissaient à vous et, en murmurant en secret des trahisons dont vous aviez été les victimes nous n'osions pas plus que vous lever nos têtes courbées sous le joug de la servitude, une stérile indignation de la conduite criminelle de nos rois envers vous était le seul hommage que nous pussions vous rendre.

Mais aujourd'hui nous sommes libres, nous sommes rentrés dans nos droits, nos oppresseurs sont punis, toutes les parties de notre administration sont régénérées et, forts de la justice de notre cause, de notre courage et des immenses moyens que nous

5 Pour les événements de l'année 1793-1794, voir Archives publiques du Canada, Collection Q, vol. 67, 68, 69-1, 69-2, 71-1 et 71-2. Le texte de la brochure est dans Q 71-1: 27-36. 
avons préparés pour terrasser tous les tyrans, il est enfin en notre pouvoir de vous venger et de vous rendre aussi libres que nous, aussi indépendants que vos voisins les Américains des EtatsUnis. Canadiens, imitez leur exemple et le nôtre, la route en est tracée, une résolution magnanime peut vous faire sortir de l'état d'abjection où vous êtes plongés. Il dépend de vous de réimprimer sur vos fronts cette dignité première que la nature a placée sur l'homme et que l'esclavage avait effacée.

L'homme est né libre. Par quelle fatalité est-il devenu le sujet de son semblable ? Comment a pu s'opérer cet étrange bouleversement d'idées, qui a fait que des nations entières se sont volontairement soumises à rester la propriété d'un seul individu ? C'est par l'ignorance, la mollesse, la pusillanimité des uns, l'ambition, la perfidie, les injustices, etc. des autres. Mais aujourd'hui que par les excès d'une domination devenue insupportable des peuples entiers, en s'élevant contre leurs oppresseurs, ont révélé le secret de leur faiblesse et dévoilé l'iniquité de leurs moyens, combien ne sont-elles pas coupables les nations qui restent volontairement dans des fers avilissants et qui, effrayées du sacrifice de quelques moments de repos, se livrent à une honteuse inertie et restent volontairement dans la servitude ? Tout autour de vous vous invite à la liberté. Le pays que vous habitez a été conquis par vos pères. Il ne doit sa prospérité qu'à leurs soins et aux vôtres. Cette terre vous appartient. Elle doit être indépendante. Rompez donc avec un gouvernement qui dégénère de jour en jour et qui est devenu le plus cruel ennemi de la liberté des peuples. Partout on retrouve des traces du despotisme, de l'avidité, des cruautés du roi d'Angleterre. Il est temps de renverser un trône où se sont trop longtemps assises l'hypocrisie et l'imposture. Que les vils courtisans qui l'entouraient soient punis de leurs crimes ou que dispersés sur le globe l'opprobre dont ils seront couverts atteste au monde qu'une tardive mais éclatante vengeance s'est opérée en faveur de l'humanité.

Cette révolution nécessaire, ce châtiment inévitable se préparent rapidement en Angleterre. Les principes républicains y font tous les jours de nouveaux progrès et le nombre des amis de la liberté et de la France y augmente d'une manière sensible. Mais n'attendez point pour rentrer dans vos droits l'issue de cet événement, travaillez pour vous, pour votre gloire, ne craignez rien de George III, de ses soldats, en trop petit nombre pour s'opposer avec succès à votre valeur. Sa faible armée est retenue en Angleterre autour de lui par les murmures des Anglais et par les immenses préparatifs de la France, qui ne lui permettent pas d'augmenter le nombre de vos bourreaux. Le moment est 
favorable et l'insurrection est pour vous le plus saint des devoirs. N'hésitez donc pas et rappelez aux hommes qui seraient assez lâches pour refuser leurs bras et leurs armes à une aussi généreuse entreprise l'histoire de vos malheurs. Les cruautés exercées par l'Angleterre pour vous faire passer sous son autorité. Les insultes qui vous ont été faites par des agents qui s'engraissaient de vos sueurs. Rappelez-leur les noms odieux de Murray et d'Haldimand, les victimes de leurs férocités. Les entraves dont votre commerce a été garrotté, le monopole odieux qui l'énerve et l'empêche de s'agrandir, les traites périlleuses que vous entreprenez pour le seul avantage des Anglais. Enfin rappelez-leur qu'étant nés Français vous serez toujours enviés, persécutés par les rois anglais et que ce titre sera plus que jamais aujourd'hui un motif d'exclusion pour tous les emplois.

En effet, des Français traiteraient leurs concitoyens en frères et se soucieraient moins de plaire au despote anglais qu'à rendre justice aux Canadiens. Ils ne s'attacheraient pas à plaire aux rois mais à leurs frères. Ils renonceraient plutôt à leurs places que de commettre une injustice. Ils préféreraient aux pensions qui leur seraient accordées la douce satisfaction d'être aimés et estimés dignes de leur origine. Ils opposeraient une vigoureuse résistance aux décrets arbitraires de la cour de Londres, de cet cour perfide qui n'a accordé au Canada une ombre de constitution que dans la crainte qu'il ne suivît l'exemple vertueux de la France et de l'Amérique, qu'en secouant son joug il ne fondât son gouvernement sur les droits imprescriptibles de l'homme.

Aussi quels avantages avez-vous retirés de la constitution qui vous a été donnée ? Depuis six mois que vos représentants sont assemblés, vous ont-ils fait présent d'une bonne loi ? Ont-ils pu corriger un abus? Ont-ils eu le pouvoir d'affranchir votre commerce de ses entraves? Non. Et pourquoi ? Parce que tous les moyens de corruption sont employés secrètement et publiquement dans vos élections pour faire pencher la balance en faveur des Anglais.

Canadiens, vous avez en vous tout ce qui peut constituer votre bonheur. Eclairés, laborieux, courageux, amis de la justice, industrieux, qu'avez-vous besoin de confier le soin de vous gouverner à un tyran stupide, à un roi imbécile dont les caprices peuvent entraver vos délibérations et vous laisser sans loi pendant des années entières. N'est-il pas aussi ridicule de confier à un pareil homme placé à l'autre extrémité du globe le soin de veiller à vos plus chers intérêts que de voir un cultivateur cana- 
dien aller se placer aux sources du Missouri pour mieux diriger son habitation.

Les hommes ont le droit de se gouverner eux-mêmes, les lois doivent être l'expression de la volonté manifestée par l'organe de ses représentants, nul n'a le droit de s'opposer à leur exécution. Et, cependant, on a osé vous imposer un odieux veto que le roi d'Angleterre ne s'est réservé que pour empêcher la destruction des abus et pour paralyser tous vos mouvements. Voilà le présent que de vils stipendiés ont osé vous présenter comme un monument de bienfaisance du gouvernement anglais. On a comparé très ingénieusement le pouvoir législatif à la tête d'un homme qui conçoit et le pouvoir exécutif aux bras du même homme qui exécute. Si les bras se refusent à ce que la tête a jugé nécessaire au bien du corps entier, privé de secours il devient malade et il meurt.

Canadiens, il est temps de sortir du sommeil léthargique dans lequel vous êtes plongés. Armez-vous, appelez à votre secours vos amis les Indiens, comptez sur l'appui de vos voisins et sur celui des Français. Jurez de ne quitter vos armes que lorsque vous serez délivrés de vos ennemis. Prenez le ciel et votre conscience à témoin de l'équité de vos résolutions et vous obtiendrez ce que les hommes énergiques ne réclament jamais en vain, la liberté et l'indépendance.

\section{Résumé des avantages que les Canadiens peuvent obtenir en se libérant de la domination anglaise}

1. Le Canada sera un Etat libre et indépendant.

2. Il pourra former des alliances avec la France et les EtatsUnis.

3. Les Canadiens se choisiront un gouvernement, ils nommeront eux-mêmes les membres du corps législatif et du pouvoir exécutif.

4. Le veto sera aboli.

5. Toutes les personnes qui auront obtenu le droit de citoyen du Canada pourront être nommées à toutes les places.

6. Les corvées seront abolies.

7. Le commerce jouira de la liberté la plus étendue.

8. Il n'y aura plus de compagnie privilégiée pour le commerce des fourrures, le nouveau gouvernement l'encouragera.

9. Les droits seigneuriaux seront abolis. Les lods et ventes, droit de mouture, de péage, réserve de bois, travaux pour le service des seigneurs, etc., etc. seront également abolis. 
10. Seront également abolis tous titres héréditaires, il n'existera plus ni lords, ni seigneurs, ni nobles.

11. Tous les cultes seront libres. Les prêtres catholiques nommés par le peuple comme dans la primitive Eglise jouiront d'un traitement analogue à leur utilité.

12. Les dîmes seront abolies.

Il sera établi des écoles dans les paroisses et dans les villes. Il y aura des imprimeries, des institutions pour les hautes sciences, la médecine, les mathématiques. Il sera formé des interprètes qui reconnus de bonnes mœurs seront encouragés à civiliser les nations sauvages et à étendre par ce moyen leur commerce avec elles.

\section{LA FRANCE A-T-ELLE PERDU OU ABANDONNÉ LE CANADA?}

Tel est le thème du prochain Cahier de l'Académie canadienne-française, en voie de publication. Sept études originales signées Lionel Groulx, Guy Frégault, Marcel Trudel, Michel Brunet, Claude Galarneau, Jean Bruchesi et Victor Barbeau.

Un magnifique volume de près de deux cents pages sur papier de luxe, à $\$ 3$. l'exemplaire. On le commande (mandat ou chèque au pair) au secrétariat de l'Académie, 535, avenue Viger, Montréal. 